\title{
Medically unexplained symptoms in primary care
}

\author{
Else Guthrie
}

\begin{abstract}
Adult patients with medically unexplained symptoms (somatisation) in primary care are numerous and make disproportionately high demands on health services. Most of these individuals are open to the suggestion that their illness reflects psychological needs. Empowering explanations from doctors can enable patient and doctor to work collaboratively in managing the problem and can reduce healthcare contacts. Parental medically unexplained symptoms, sexual and physical abuse in childhood and childhood neglect are associated with a greater risk of medically unexplained symptoms in adulthood. The overall prognosis for the majority of primary care patients with medically unexplained symptoms is very good. The two most common approaches to dealing with medically unexplained symptoms in primary care are stepped-care approaches and teaching general practitioners new skills to manage consultations more effectively.
\end{abstract}

An estimated $15-30 \%$ of all primary care consultations are for medically unexplained symptoms (Kirmayer et al, 2004). Patients with such symptoms receivelarge amounts of symptomatic investigation and treatment (Barsky \& Borus, 1999). The number of medically unexplained symptoms over a person's lifetime correlates linearly with the number of depressive and anxiety disorders experienced (Katon \& Walker, 1998). However, numerous somatic symptoms or illness worry cannot be solely explained by concurrent anxiety and depression (Creed \& Barsky, 2004).

The terminology in relation to these problems is unsatisfactory and stigmatising. The term 'somatisation' is widely used, indicating the psychological process by which psychological distress is transformed into somatic symptoms. There is little evidence, however, that this process actually occurs, although psychological factors undoubtedly play a role in the development and maintenance of many physical complaints. The term 'medically unexplained symptoms' is preferred by many general practitioners (GPs) and primary care researchers, as this nomenclature does not imply any sense of psychological causation.

Medically unexplained syndromes such as irritable bowel syndrome, chronic pelvic pain, fibromyalgia and chronic fatigue syndrome are characterised by clusters of symptoms that suggest a shared underlying malfunction of a particular bodily system (i.e. gastrointestinal, reproductive, neuromuscular, neurological). However, a number of studies have shown that these syndromes often overlap. For instance, $70 \%$ of patients with debilitating fatigue lasting more than 6 months also have diffuse muscle pain (fibromyalgia or chronic widespread pain) (Buchwald \& Garrity, 1994). Similar overlaps occur between irritable bowel syndrome, atypical non-cardiac chest pain, chronic fatigue and gynaecological syndromes. In primary care there is little evidence to support the existence of discrete somatic syndromes (Stanley et al, 2002). Apparent differences between syndromes are usually the result of artificial distinctions made on the basis of presenting complaint, physician interest and service configuration. Symptombased classifications often reflect access to care, which may result in a 'narrow focus' and multiple referrals to different specialists.

\section{Doctor-patient interactions}

The way symptoms are presented to doctors is shaped by the social context in which the symptom is experienced (e.g. intolerable job, marital discord) and presented (to a GP, psychiatrist), the beliefs

Else Guthrie is a consultant in psychological medicine at Manchester Royal Infirmary and Honorary Professor of Psychological Medicine, University of Manchester (Rawnsley Building, Manchester Royal Infirmary, Oxford Road M13 9WL, UK. Email: elspeth.a.guthrie@ manchester.ac.uk). Professor Guthrie is currently Chair of the Liaison Faculty of the Royal College of Psychiatrists and has conducted research over the past 20 years into the aetiology and management of medically unexplained symptoms. 
and expectations of the patient and the diagnostic language of the physician.

Patients form explanatory models of the likely causation of their symptoms on the basis of biomedical ideas and social constructions, both current and outdated (Stimson, 1974; Shorter, 1995). For example, many people believe that any kind of pain in the chest must be caused by problems with the heart. However, by definition, medically unexplained symptoms do not have an organic explanation. Reassuring a patient that there is nothing seriously wrong is a challenging, complex and poorly understood part of medical practice.

\section{The doctor's explanation}

Work in the UK suggests that patients with medically unexplained symptoms perceive the explanations that their GPs give them as being at odds with their own thinking (Salmon et al, 1999). The study involved analysis of almost 200 patients' accounts of their GPs' explanations of symptoms, which the researchers categorised according to three types: rejecting, colluding or empowering (Table 1). In most cases, the reported explanations were categorised as a rejection of the patients' suffering. Some were categorised as 'colluding' and only a minority of explanations were experienced as empowering.

Explanations that patients perceived as rejecting resulted in conflict and patients were unlikely to trust doctors in relation to future or continuing symptoms. Collusive explanations were less likely

$\begin{aligned} & \text { Table } 1 \text { Types of explanation of patients' symptoms } \\ & \text { given by doctors }\end{aligned}$
$\begin{aligned} & \text { Type of } \\ & \text { explanation }\end{aligned}$
$\begin{array}{ll}\text { Rejecting } & \begin{array}{l}\text { Thplications for the patient } \\ \text { patients' symptoms } \\ \text { The doctor implies that the } \\ \text { problem is imaginary or related to } \\ \text { a psychological problem, which the } \\ \text { patient perceives as stigmatising }\end{array} \\ & \begin{array}{l}\text { The doctor acquiesces to the } \\ \text { explanation offered by the patient }\end{array} \\ \text { Colluding } & \begin{array}{l}\text { The doctor provides a physical } \\ \text { mechanism of causation }\end{array} \\ \text { Empowering } & \begin{array}{l}\text { The doctor removes any sense of } \\ \text { blame from the patient }\end{array} \\ \text { The doctor strengthens the } \\ \text { relationship with the patient, enabling } \\ \text { them to resolve the problem together }\end{array}$
Source: Salmon et al (1999).

to result in conflict but led patients to question doctors' competence or to perceive them as being very passive or having little interest in patients' problems. Empowering explanations had the effect of removing blame and enabling patients to develop appropriate mind-body models, leading to greater involvement in their own treatment.

\section{Metaphors of illness}

When patients describe unexplained symptoms, the most striking feature of their account is their conviction that their symptoms are real and so 'must be caused by something'. To a large extent, patients understand their symptoms by using metaphors. For example, the metaphor of plumbing underlies ideas of blockage and pressure in the body, whereas beliefs that the body lacks energy or that part of it is worn out use a metaphor of the body as a machine. These physical explanations are consistent with patients' essentially physical concept of the body and its functions. Psychological conditions such as depression can be conceptualised as being caused by an alteration in neuronal function in the brain. Such explanations may be considered by some doctors as overly medical but they remove any sense of blame and provide a metaphor for understanding a complex bio-psychosocial disorder. They also strengthen the doctor-patient alliance and provide a platform from which other, perhaps more psychosocial, issues can be explored in safety.

Most patients with medically unexplained symptoms in primary care allow doctors the opportunity to address their psychological needs (Salmon et al, 2004; Ring et al, 2005). During nearly all consultations about their symptoms, patients provide cues: they may mention 'stress', or suggest that disease may be absent, or make tentative references to serious disease. In general, however, doctors do not engage with these cues, so the opportunities for exploring psychosocial issues are often lost. General practitioners are more likely to suggest physical treatment for medically unexplained symptoms than patients are to request it (Ring et al, 2005), which suggests that one of the main explanations for why people 'somatise' should be sought in the processes that underlie doctor-patient consultations.

\section{Normalisation}

One of the most common responses by doctors in consultations with patients with medically unexplained symptoms is to try to normalise the symptoms. This approach occurs in over $70 \%$ of cases (Dowrick et al, 2004). Dowrick et al have 
Table 2 Classification of normalisation by general practitioners

\begin{tabular}{ll}
$\begin{array}{l}\text { Type of normalisation } \\
\text { Without explanation }\end{array}$ & $\begin{array}{l}\text { Features } \\
\text { Rudimentary explanation } \\
\text { and dismissal of disease }\end{array}$ \\
$\begin{array}{l}\text { With ineffective } \\
\text { explanation }\end{array}$ & $\begin{array}{l}\text { Physical mechanism } \\
\text { used but unconnected to } \\
\text { patients' concerns } \\
\text { With effective }\end{array}$ \\
explanation & $\begin{array}{l}\text { Appropriate physical } \\
\text { metaphor connection of } \\
\text { physical and psychological } \\
\text { factors }\end{array}$ \\
\hline Source: Dowrick et al (2004). &
\end{tabular}

described three different types of normalising strategies that GPs use (Table 2). The most frequently used of these involves dismissing or rejecting the patient's concerns. Often, negative test results are used as confirmation that there is nothing wrong and little or no explanation is offered for the cause of the symptoms (Box 1). The most likely outcome of this type of consultation is some kind of somatic action, for example a prescription, referral or further investigation. Some doctors attempt an explanation using a physical mechanism but this can fail to connect with the patient's concerns and once again the most likely outcome is further investigation or treatment. In a small proportion of consultations, doctors explain the patient's symptoms in terms of tangible, physical mechanisms. These explanations often allow the patient to share the responsibility of managing the physical symptom and sometimes include reference to emotional concerns or symptoms (Box 2). Dowrick and colleagues found that patients perceive such consultations as being more helpful,

Box 1 A normalising response without explanation

Patient: 'The other thing, my stomach is very extended at the moment... I'm finding now everything I eat, it used to be high-fat foods like chips or you know a curry or something like that, but now it's everything I eat, my stomach is really swollen. I notice certain clothes I just can't wear now, you know at certain times because my stomach's really...'

Doctor: 'Just get bloated, do you?'

(Reproduced from Dowrick et al, 2004)
Box 2 A normalising response with effective explanation

Doctor: 'Is that sore there?'

Patient: 'Yes.'

Doctor: 'Yes. It's the big muscle group isn't it? It feels quite tense on this side as well actually. Think that's with all the tension and stress? How are things working out?'

Patient: 'Finding it a bit difficult... because a sort of people go through the motions you know, of being very busy and getting paid for doing, you know, passing pieces of paper around. I was going spare on Friday.'

(Reproduced from Dowrick et al, 2004)

and they are less likely to result in negative overinvestigation or inappropriate referral.

Reassurance is ineffective unless doctors find out what is troubling or concerning the patient. Explanations that address the patient's concerns without undermining or invalidating their experiences are most likely to be of help to people who have these difficult and complex problems.

Recent,innovativeworkhassoughttounderstand why GPs provide somatic interventions for patients with medically unexplained symptoms (Salmon et al, 2006). One long-standing assumption has been that patients with medically unexplained symptoms demand investigation and treatment. This, however, is not the case: the main reason GPs instigate investigation and treatment is to end a consultation in which the patient is elaborating at length on their symptoms. It appears that GPs find it difficult and uncomfortable to discuss with a patient physical symptoms that they believe do not have an organic basis. Although the patient may persist in talking about their symptoms in order to pressurise the doctor into referring or treating, the most likely explanation is that their worries or concerns have not been addressed during the consultation.

\section{Doctors' attitudes}

Most GPs believe that patients with medically unexplained symptoms should be managed in primary care. A recent survey of 284 randomly selected GPs in the south of England suggested that GPs feel that they play an important role in providing reassurance and counselling for such patients and in acting as 'gatekeepers' to prevent inappropriate investigations (Reid et al, 2001). It seems that the majority of GPs believe that these 
patients have emotional problems and that there are few effective treatments available. Thus, GPs consider managing patients with medically unexplained symptoms to be an important part of their workload, but that effective management strategies are lacking. This is one area in which liaison psychiatrists, old age psychiatrists and child and adolescent liaison psychiatrists may be able to offer more help and support to GPs by linking more effectively with primary care.

Patients with intractable or persistent medically unexplained symptoms have been described as 'heartsink patients' in the medical literature, reflecting the feelings of helplessness and frustration that can be experienced by GPs who are caring for them. Such patients, however, are not representative of most people with these symptoms and it is preferable to avoid such terms.

Recent changes in the organisation and delivery of healthcare in the UK have meant that many patients previously treated in secondary care are now managed in primary care. The boundary between primary and secondary care is becoming increasingly blurred, with the proposed development of polyclinics and other services that span the primary/secondary care interface. Liaison psychiatrists are likely to be of most help in the overall planning and development of services, supervision of staff and management of complex cases. Attachments to liaison psychiatry by GP trainees may be of particular benefit as they will receive expert instruction in the treatment and management of patients with medically unexplained symptoms. This will range from a knowledge of brief interventions (pharmacological and psychological) to the long-term management of more complex cases. Trainees should be encouraged to learn how to elicit patients' beliefs regarding their symptoms, to engage patients in a clinical dialogue, to pick up emotional cues, to provide effective explanations for symptoms, and to engage patients in simple treatment strategies.

\section{Conceptual issues}

For most illnesses (e.g. peptic ulcers, upper respiratory tract symptoms, back pain) there is a very poor correlation between symptoms and observed pathological changes. Differences in sensitivity to painful stimuli are both biologically and psychosocially conditioned. Personality traits and values also affect the reporting of physical symptoms.

Furthermore, it is normal to experience emotions in the body and for bodily symptoms to be accompanied by emotional distress. Thus, emotions are simultaneously experienced in the emotional and somatic processing areas of the brain. This understanding of emotions is discordant with the distinctions between somatic and psychological symptoms in modern medicine. The bio-psychosocial model addresses the central challenge of reconciling the patient's and the doctor's perspectives, and incorporates recent research in psychology and neurobiology. Although patients may use various models to explain illness, it is clear that a conceptual understanding of symptoms is important and determines to a large extent how people react and behave in relation to their symptoms.

\section{The psychology of symptoms}

So what role, if any, do psychological factors play in the development of medically unexplained symptoms?

In recent years, there has been a growth of research that encompasses both biological and psychosocial aspects of medically unexplained symptoms (Box 3). These include early-life experiences that may shape future responses to stress and current events that may precipitate the development of symptoms.

\section{Box 3 Further reading}

Medically unexplained symptoms

- Burton, C. (2003) Beyond somatisation: a review of the understanding and treatment of medically unexplained symptoms (MUPS). British Journal of General Practice, 53, 233-214.

- Eminson, D. M. (2001) Somatising in children and adolescents. 1. Clinical presentations and aetiological factors. Advances in Psychiatric Treatment, 7, 266-274.

- Eminson, D. M. (2001) Somatising in children and adolescents. 2. Management and outcomes. Advances in Psychiatric Treatment, 7, 388-398.

- Page, L. \& Wessely, S. (2007) Functional somatic syndromes. In Handbook of Liaison Psychiatry (eds G. G. Lloyd \& E. Guthrie), pp. 125-148. Cambridge University Press.

Frequent attendance in primary care

- Kapur, N. (2007) Frequent attenders in primary care. In Handbook of Liaison Psychiatry (eds G. G. Lloyd \& E. Guthrie), pp. 871-895. Cambridge University Press. 


\section{Intergenerational transmission}

The children of parents who present with medically unexplained symptoms are at greater risk of developing such symptoms than are the offspring of parents with organic medical conditions (Levy et al, 2001; Craig et al, 2002). For example, children of parents with irritable bowel syndrome make $25 \%$ morehealthcarevisits peryear for similar symptoms than children of parents without the syndrome (Levy et al, 2000). Although genetic factors may make a small contribution, the evidence suggests that most of this behaviour is best understood by social learning. Children with recurrent abdominal pain in childhood have higher levels of anxiety and depression than healthy children, and high levels of depression predict persistent symptoms over a 5 -year period (Walker et al, 1998).

Psychological factors are also more predictive of the development of back pain in teenage children than are mechanical factors (Jones et al, 2003). Children with high levels of somatic symptoms generally also show lower academic competence, are at particular risk of avoiding school in response to abdominal pain and worry more about illness (Eminson et al, 1996). Children with more aches and pains, tiredness and fatigue are more likely than their peers to develop anxiety and depression (Campoet al, 2004). This may become an established pattern that persists into adulthood. Having an illness as a child or witnessing illness in a close adult may influence the development of physical symptoms as an adult (Craig et al, 1993).

\section{Abuse in childhood}

Sexual and physical abuse and neglect in childhood are linked to a greater risk of both psychological and physical problems in adulthood. Children who experience such problems may also have difficulty with schooling and often come from families that are unable to provide support and consistent care. A history of childhood adversity is common in patients with medically unexplained symptoms in primary care (Schilte et al, 2001).

\section{Environmental stressors}

In adults, environmental stressors such as divorce or bereavement can precipitate both psychological reactions and somatic syndromes. The development of a particular physical complaint may be the result of complex interactions between physiological systems and social/psychological processes. For example, the development of irritable bowel syndrome following a gut infection appears to be dependent on both the inflammatory process and
Table 3 Illness beliefs in relation to symptoms

\begin{tabular}{|c|c|}
\hline Belief & Symptom \\
\hline Normalising & $\begin{array}{l}\text { I'm tired because I've been } \\
\text { working too hard }\end{array}$ \\
\hline Somatic & I'm tired because I've got a virus \\
\hline Psychological & $\begin{array}{l}\text { I'm tired because I've been } \\
\text { stressed }\end{array}$ \\
\hline
\end{tabular}

the psychological status of the individual at the time the gut infection occurred. Chronic life stress (e.g. a very unhappy or abusive marriage, or a partner with a terminal illness) may prolong medically unexplained symptoms. One study of individuals with irritable bowel syndrome reported that few participants experiencing chronic life stress improved over a 2-year period: improvement occurred only in those who were free of chronic stress or in whom the stress was resolved (Bennett et al, 1998).

\section{Illness beliefs and perceptions}

Illness beliefs (Table 3) have a major influence on the decision to seek medical care and on communication between patient and doctor (Sensky et al, 1996). Patients with medically unexplained symptoms have more negative illness perceptions and poorer health status than patients without such symptoms (Frostholm et al, 2007). Negative emotional representations of symptoms and uncertainty regarding their nature predict poor patient satisfaction with consultations (Frostholm et al, 2005). Negative perceptions of illness are associated with poor physical and mental health, and strongly predict lack of improvement or deterioration in health status over 2 years (Frostholm et al, 2007).

\section{Frequent attendance in primary care}

Some people consult doctors more frequently than others. Some hardly ever see a GP. Frequent consultation may be sporadic, for a 'time-limited' condition such as pregnancy, or continuous, because of a chronic physical illness. Since we are all more likely to develop physical problems as we get older, the highest consultation rates in primary care are among the elderly. Consultation rates may also be practice-specific, owing to the varied populations that different practices serve and the individual practice of GPs (Neal et al, 1998). 
Box 4 Factors independently associated with consultation in primary care

- Negative attitudes towards illness

- The presence of physical and psychiatric disorder

- Health anxiety

- Changes in psychological distress

- Reported physical symptoms

- Age

- Gender

(Kapur et al, 2004)

\section{Definition of terms}

To avoid bias in defining frequent attendance, one study of frequent attenders in primary care (in the UK and Spain) stratified mean consultation rates in a series of GP practices for age and gender, and defined frequent attendance as an annual rate of consultation at least twice as high as the practice's gender- and age-related mean (Dowrick et al, 2000).

Another way of looking at consultation frequency in primary care is to consider factors that may contribute to it. A longitudinal cohort study identified factors that independently predicted primary care consultation over a 5-year period (Kapur et al, 2004). Data were obtained on 738 patients, who accounted for 12182 consultations. Box 4 shows the factors that were independently associated with consultations over the period of the study. Psychological distress was more strongly associated with consultation in women than men, whereas cognitive factors (negative attitudes) were more strongly associated with the consultation rate in men (Kapur et al, 2005). These variables together accounted for a difference of 10 consultations per person per year between groups. Other researchers have found that psychological distress increases the risk of future frequent attendance among adult patients consulting family practices in the daytime about illness (Vedsted et al, 2001). Depressive symptoms were the major predictor of frequent attendance in primary care populations in the UK and Spain (Dowrick et al, 2000). Parental anxiety, depression and physical symptoms are important factors affecting consultation rates for children.

\section{Elderly patients}

The importance of medically unexplained symptoms among older primary care attenders is unclear. Frequent attenders over 65 years of age have higher rates of depression, physical illness and medically unexplained symptoms and lower perceived social support than elderly patients who attend less frequently (Sheehan et al, 2003). This suggests that in addition to physical illness, psychological distress and social isolation may influence consultation in this age group, and doctors should be aware of this. However, elderly patients with medically unexplained symptoms may be no more likely to have depression than patients of the same age group with clear organic disease (Sheehan et al, 2004).

\section{Treatment}

There are no proven treatments in the primary care setting for medically unexplained symptoms, although antidepressants and several psychological interventions have been shown to be effective in secondary care. Interventions in primary care usually need to be relatively easy to administer, brief and accessible. Studies have mainly involved either the training of health professionals in new skills to manage consultations more effectively, or a stepped-care approach. However, one of the best researched interventions for medically unexplained symptoms in primary care is the reattribution model developed by researchers in Manchester and Liverpool (Morriss et al, 2006).

\section{Reattribution}

The model, as it is currently employed, involves four stages (Box 5). The first stage requires the GP to take a full history of the patient's symptoms, to listen to their story of how they developed and to carry out a focused physical examination. Stage two involves feeding back information to the patient, including the results of any physical examination, and acknowledging the worry and concern caused by symptoms. The doctor should also pick up and / or acknowledge any cues regarding psychosocial distress. In the third stage, the doctor links the patient's symptoms to appropriate psychosocial issues using a normalisation approach and provides a credible aetiological mechanism. Finally, the

\section{Box 5 The reattribution model}

Stage 1 Feeling understood

Stage 2 Broadening the agenda

Stage 3 Making the link

Stage 4 Negotiating treatment

(Adapted from Morriss et al, 2006) 
doctor discusses and negotiates with the patient possible treatment or management options.

Reattribution techniques have been evaluated in a small number of randomised controlled trials (RCTs) in primary care involving patients with medically unexplained symptoms. In a German study comparing training about depression and anxiety with and without reattribution, the reattribution group reported improved physical symptoms at 3 and 6 months, and physical function and depression at 3 months (Larisch et al, 2004). In a trial in The Netherlands, reattribution improved subjective health and reduced distress from physical symptoms at 12 and 24 months (Blankenstein et al, 2002). In a large Danish study, reattribution resulted in improved physical function (Rosendal et al, 2003). Morriss et al (2006) have recently reported on a definitive, cluster RCT of reattribution training for family practitioners in involving 16 practices and 70 GPs. All GPs recruited to the reattribution limb completed training and found it helpful. This suggests that reattribution is acceptable to GPs and training can be delivered to whole practices.

Reattribution was the control intervention in a different type of specific communication training recently evaluated in a cluster RCT involving 39 GPs and 156 patients with medically unexplained symptoms (Aiarzaguena et al, 2007). Doctors in the intervention group were trained in techniques that focused on offering a physical explanation for medically unexplained symptoms and indirectly approaching sensitive topics. Patients in both groups improved in all dimensions of quality of life.

\section{Stepped care and psychosocial interventions}

A group in the USA conducted an RCT of multidimensional stepped care consisting of cognitivebehavioural, pharmacological and other treatment modalities. During the 12-month trial, which involved 206 patients, 48 in the treatment group improved compared with 34 in the control group (Smith et al, 2006). Expenditure on antidepressants was significantly higher in the intervention group than in the control group, but the difference in total costs over the 12-month intervention was not significant, which suggests the intervention may be cost-effective (Luo et al, 2007).

Cognitive-behavioural group therapy (Lidbeck, 1997) involving eight sessions of treatment has been compared with a waiting-list condition. At 6-month follow-up, individuals in the treatment group showed improvement in illness behaviour, hypochondriasis and medication use, but not
Box 6 Factors associated with poor prognosis

- Somatic symptoms that have lasted for more than 2 years

- Childhood physical or sexual abuse

- History of psychiatric disorder

- Ongoing severe psychosocial stressors

in social problems, anxiety, depression or sleep. Martin et al (2007) have recently shown that even one session of psychological therapy may help reduce the number of primary care visits and somatisation severity in patients with medically unexplained symptoms.

A recently updated Cochrane review on psychosocial interventions by GPs rated the evidence for treatments for somatisation as 'limited' (Huibers et al, 2007).

\section{Pharmacotherapy}

There has been very little work on the efficacy of antidepressants for medically unexplained symptoms in primary care, although there is good evidence from studies performed mainly in the secondary sector that these drugs are helpful (O'Malley et al, 1999). Benefit is not dependent on the presence of depression and much smaller doses are required than those usually used to treat depression. The best evidence is for tricyclic antidepressants, although care should always be taken when prescribing these drugs because of their potential lethality in overdose.

\section{Prognosis}

The overall prognosis for the majority of patients withmedicallyunexplained symptomsisvery good. In about $70 \%$ of patients, symptoms spontaneously remit within a few months of presentation. Other patients adapt and find ways to cope with their symptoms. However, nearly a third of patients' problems become chronic, leading to poor quality of life and high consultation rates (Craig et al, 1993). Factors associated with a poor prognosis are shown in Box 6.

A population study from Norway in which over 400 people were assessed for recent medically unexplained symptoms at baseline and again 11 years later showed that women had a 2.5 times higher risk of experiencing such symptoms than men (Leiknes et al,2007). The study also showed that there was an inverse relationship between age and 
recent onset of symptoms (i.e. older people were less likely to report symptoms). The presence of an anxiety disorder 11 years earlier was associated with a twofold risk of having developed medically unexplained symptoms at follow-up; depression at follow-up was associated with current reports of medically unexplained symptoms.

\section{Conclusions}

Medically unexplained symptoms are common in primary care and result in much symptomatic investigation and treatment. The problems underlying these symptoms are often complex and may have physical, physiological, psychological and social dimensions. Patients presenting with such symptoms often feel undermined or misunderstood by doctors, as patients and doctors often have different agendas. The challenge is for doctors to find ways of engaging with the patients that do not directly challenge the patients' belief in the reality of their symptoms, but allow discourse about other aetiologies and influencing factors. Further work is required before any treatment for this perplexing problem can be definitively established as being of proven benefit in primary care.

\section{Declaration on interest}

None.

\section{References}

Aiarzaguena, J. M., Grandes, G., Gaminde, I., et al (2007) A randomized controlled clinical trial of a psychosocial and communication intervention carried out by GPs for patients with medically unexplained symptoms. Psychological Medicine, 37, 283-294.

Barsky, A. J. \& Borus, J. F. (1999) Functional somatic syndromes. Annals of Internal Medicine, 130, 910-921.

Bennett, E. J., Tennant, C. C., Piesse, C., et al (1998) Level of chronic life stress predicts clinical outcome in irritable bowel syndrome. Gut, 43, 256-261.

Blankenstein, A. H., van der Horst, H. E., Schilte, A. F., et al (2002) Development and feasibility of a modified reattribution model for somatising patients applied by their own general practitioners. Patient Education and Counseling, 47, 229-235.

Buchwald, D. \& Garrity, D. (1994) Comparison of patients with chronic fatigue syndrome, fibromyalgia, and multiple chemical sensitivities. Archives of Internal Medicine, 154, 2049-2053.

Campo, J. V., Bridge, J., Ehmann, M., et al (2004) Recurrent abdominal pain, anxiety, and depression in primary care. Pediatrics, 113, 817-824.

Craig, T. K., Boardman, A. P., Mills, K., et al (1993) The South London Somatisation Study. I: Longitudinal course and the influence of early life experiences. British Journal of Psychiatry, 163, 579-588.

Craig, T. K., Cox, A. D. \& Klein, K. (2002) Intergenerational transmission of somatization behaviour: a study of chronic somatizers and their children. Psychological Medicine, 32, 805-816.

Creed, F. \& Barsky, A. (2004) A systematic review of the epidemiology of somatisation disorder and hypochondriasis. Journal of Psychosomatic Research, 56, 391-408.
Dowrick, C., Bellón, J. \& Gómez, M. (2000) GP frequent attendance in Liverpool and Granada: the impact of depressive symptoms. British Journal of General Practice, 50, 361-365.

Dowrick, C. F., Ring, A.,Humphris, G. M., et al (2004)Normalisation of unexplained symptoms by general practitioners: a functional typology. British Journal of General Practice, 54, 165-70.

Eminson, D. M., Benjamin, S., Shortall, A., et al (1996) Physical symptoms and illness attitudes in adolescents: an epidemiological study. Journal of Child Psychology and Psychiatry, 37, 519-528.

Frostholm, L., Fink, P., Oernboel, E., et al (2005) The uncertain consultation and patient satisfaction: the impact of patients' illness perceptions and a randomized controlled trial on the training of physicians' communication skills. Psychosomatic Medicine, 67, 897-905.

Frostholm, L., Oernboel, E., Christensen, K. S., et al (2007) Do illness perceptions predict health outcomes in primary care patients? A 2-year follow-up study. Journal of Psychosomatic Research, 62, 129-138.

Huibers, M. J. H., Beurskens, A. J. H. M., Bleijenberg, G., et al (2007) Psychosocial interventions by general practitioners. Cochrane Database of Systematic Reviews, issue 3, CD003494.

Jones, G. T., Watson, K. D., Silman, A. J., et al (2003) Predictors of low back pain in British schoolchildren: a population-based prospective cohort study. Paediatrics, 111, 822-828.

Kapur, N., Hunt, I., Lunt, M., et al (2004) Psychosocial and illness related predictors of consultation rates in primary care - a cohort study. Psychological Medicine, 34, 719-728.

Kapur, N., Hunt, I., Lunt, M., et al (2005) Primary care consultation predictors in men and women: a cohort study. British Journal of General Practice, 55, 108-113.

Katon, W. \& Walker, E. A. (1998) Medically unexplained symptoms in primary care. Journal of Clinical Psychiatry, 59, 15-21.

Kirmayer, L. J., Groleau, D., Looper, K. J., et al (2004) Explaining medically unexplained symptoms. Canadian Journal of Psychiatry, 49, 663-671.

Larisch, A., Schweickhardt, A., Wirsching, M., et al (2004) Psychosocial interventions for somatizing patients by the general practitioners: a randomized controlled trial. Journal of Psychosomatic Research, 57, 507-514.

Leiknes, K. A., Finset, A., Moum, T., et al (2007) Course and predictors of medically unexplained pain symptoms in the general population. Journal of Psychosomatic Research, 62, 119-128.

Levy, R. L., Whitehead, W. E., Von Korff, M. R., et al (2000) Intergenerational transmission of gastrointestinal illness behaviour. American Journal of Gastroenterology, 95, 451-456.

Levy, R. L., Jones, K. R., Whitehead, W. E., et al (2001) Irritable bowel syndrome in twins: heredity and social learning etiology. Gastroenterology, 121, 799-804.

Lidbeck, J. (1997) Group therapy somatization disorders in general practice: effectiveness of a short cognitive-behavioural treatment model. Acta Psychiatrica Scandinavica, 96, 14-24.

Luo, Z., Goddeeris, J., Gardiner, J. C., et al (2007) Costs of an intervention for primary care patients with medically unexplained symptoms: a randomised controlled trial. Psychiatric Services, 58, 1079-1086.

Martin, A., Rauh, E., Fichter, M., et al (2007) A one-session treatment for patients suffering from medically unexplained symptoms in primary care: a randomized clinical trial. Psychosomatics, 48, 294-303.

Morriss, R., Dowrick, C., Salmon, P., et al (2006) Turning theory into practice: rationale, feasibility and external validity of an exploratory randomized controlled trial of training family practitioners in reattribution to manage patients with medically unexplained symptoms (the MUST). General Hospital Psychiatry, 28, 343-351.

Neal, R. D., Heywood, P. L., Morley, S., et al (1998) Frequency of patients' consulting in general practice and workload generated by frequent attenders: comparison between practices. British Journal of General Practice, 48, 895-898.

O'Malley, P. G., Jackson, J. L., Santoro, J., et al (1999) Antidepressant therapy for unexplained symptoms and symptom syndromes. Journal of Family Practice, 48, 980-990.

Reid, S., Whalley, D., Crayford, T., et al (2001) Medically unexplained symptoms - GP's attitudes towards their cause and management. Family Practice, 18, 519-523. 
Ring, A., Dowrick, C. F., Humphris, G. M., et al (2005) The somatising effect of clinical consultation: what patients and doctors say and do not say when patients present medically unexplained physical symptoms. Social Science and Medicine, 61, 1505-1515.

Rosendal, M., Bro, F., Fink, P., et al (2003) Diagnosis of somatisation: effect of an educational intervention in a cluster randomised controlled trial. British Journal of General Practice, 53, 917-922.

Salmon, P., Peters, S. \& Stanley, I. (1999) Patients' perceptions of medical explanations for somatisation disorders: qualitative analysis. $B M I, 318,372-376$.

Salmon, P., Dowrick, C., Rine, A., et al (2004) Voiced but unheard agendas: qualitative analysis of the psychosocial cues that patients with unexplained symptoms present to general practitioners. British Journal of General Practice, 54, 171-176.

Salmon, P., Humphris, G. M., Ring, A., et al (2006) Why do primary care physicians propose medical care to patients with medically unexplained symptoms? Anew method of sequence analysis to test theories of patient pressure. Psychosomatic Medicine, 68, 570-577.

Schilte, A. F., Portegijs, P. J., Blankenstein, A. H., et al (2001) Indicators of childhood adversity in somatisation in general practice. Scandinavian Journal of Primary Health Care, 19, 232-236.

Sensky, T., MacLoed, A. K. \& Rigby, M. F. (1996) Causal attributions about common somatic sensations among frequent general practice attenders. Psychological Medicine, 26, 641-646.

Sheehan, B., Bass, C., Briggs, R., et al (2003) Somatisation among older primary care attenders. Psychological Medicine, 33, 867877.

Sheehan, B., Bass, C., Briggs, R., et al (2004) Do general practitioners believe that their older patients' physical symptoms are somatised? Journal of Psychosomatic Research, 56, 313-316.

Shorter, E. (1995) Sucker-punched again! Physicians meet the disease of the month syndrome. Journal of Psychosomatic Research, 39, 115-118.

Smith, R. C., Lyles, J. S., Gardiner, J. C., et al (2006) Primary care clinicians treat patients with medically unexplained symptoms: a randomized controlled trial. Journal of General Internal Medicine, 21, 671-677.

Stanley, I. M., Peters, S. \& Salmon, P. (2002) A primary care perspective on prevailing assumptions about persistent medically unexplained physical symptoms. International Journal of Psychiatry in Medicine, 32, 125-140.

Stimson, G. V. (1974) Obeying doctor's orders: a view from the other side. Social Science and Medicine, 8, 97-104.

Vedsted, P., Fink, P., Olesen, F., et al (2001) Psychological distress as a predictor of frequent attendance in family practice: a cohort study. Psychosomatics, 42, 416-422.

Walker, L. S. \& Heflinger, C. A. (1998) Quality of life predictors in paediatric abdominal pain patients: findings at initial assessment and five years. In Measuring Health-related Quality of Life in Children and Adolescents: Implications for Research and Practice (ed D. D. Drotar), pp. 237-252. Lawrence Erlbaum.

\section{MCQs}

1 Adult patients with medically unexplained symptoms in primary care:

a are uncommon

b have symptoms inadequately explained by relevant organic disease

c have a poor prognosis

d are more likely to be male than female

e are more likely to be over 50 years of age.

2 A poor prognosis in primary care patients with medically unexplained symptoms is associated with:

a ongoing severe psychosocial stress

b a childhood free from sexual abuse

c being married

d symptoms for less than 6 months

e symptoms for more than 6 months.

3 Reattribution involves the following stages:

a confiding

b negotiating treatment

c feeling ignored

d breaking the link

e narrowing the agenda.

4 Factors independently associated with frequent consultation in primary care include:

a positive attitudes towards illness

b the absence of physical and psychiatric disorder

c health anxiety

d older age

e being male.

5 Patients with medically unexplained symptoms in primary care:

a provide doctors with opportunities to address psychological needs

b demand further treatment and referral to secondary care

c do not want an explanation for their symptoms

d never provide cues about psychosocial problems

e feel frustrated by explanations that involve a tangible mechanism of causation.

\section{MCQ answers}

\begin{tabular}{|c|c|c|c|c|}
\hline 1 & 2 & 3 & 4 & 5 \\
\hline a $F$ & a $\mathrm{T}$ & a F & a F & a $\mathrm{T}$ \\
\hline b $\mathrm{T}$ & $b F$ & b T & b F & $b F$ \\
\hline c F & c F & c F & c $\mathrm{T}$ & c F \\
\hline d F & d F & d F & d F & d F \\
\hline e F & e $F$ & e $F$ & e F & e $F$ \\
\hline
\end{tabular}

